\title{
Prevalence and Correlates of Depression and Anxiety in Quarantined Population During the COVID-19 Outbreak in Central Ethiopia
}

Mebratu abraha Kebede ( $\square$ mebratuabraha21@gmail.com )

Barts and The London School of Medicine and Dentistry

Getinet Ayano

Curtin University Bentley Campus: Curtin University

Dereje Bayissa

Millenium Medical College

Abraham Getachew

Millenium Medical College

Mahteme Bekele

Millenium Medical College

Melsew Getnet

Millenium City Academy

Melaku Seyum

Ethiopian Public Health Institute

Atkure Molla

Ethiopian Public Health Institute

Sileshi Demelash

Ethiopian Public Health Institute

Gizachew Taddesse

Ethiopian Public Health Institute

Tariku Shimels

Millenium Medical Collge

Research

Keywords: Anxiety, Depression, psychological problems, COVID-19, Ethiopia

Posted Date: February 25th, 2021

DOI: https://doi.org/10.21203/rs.3.rs-248456/v1 
License: (c) (i) This work is licensed under a Creative Commons Attribution 4.0 International License. Read Full License 


\section{Abstract}

Background: Since the declaration of coronavirus disease 2019 (COVID-19) outbreak as a pandemic, different countries across the globe have been using quarantine to decrease the transmission of the disease and subsequently to minimize morbidity and associated mortality. Evidence suggests that quarantine might have a wide-ranging, substantial, and long-lasting negative psychological impact especially when the necessary preventive measures are not taken. However, to the best of our knowledge, there are no prior studies that determined the prevalence and correlate of depression and anxiety in quarantined populations during the COVID-19 outbreak in Sub-Saharan Africa including Ethiopia.

Methods: A community-based cross-section study was conducted among individuals under quarantine from June 5 to July 5, 2020. After obtaining verbal consent, data was collected face to face using the structured and self-administered hospital anxiety and depression scale instrument. Hospital Anxiety and Depression Scale (HADS) was used to assess depression and anxiety. Binary logistic regression analysis (multivariate analysis) was used to identify the potential determinants of depression and anxiety.

Result: A total of 297 participants were included in the study which makes the response rate $90.8 \%$. The prevalence of anxiety, depression, and co-morbid anxiety and depression were $21.5 \%, 70.7 \%$, and $15.8 \%$ respectively. In our multivariable analyses, stressful life events (AOR $2.61,95 \% \mathrm{Cl}(1.46,4.67)$ ), spent time on sleeping (AOR 1.97, 95\% Cl $(1.08,3.62)$ ), and believing that COVID-19 could be prevented by wearing a glove (AOR $0.30,95 \% \mathrm{Cl}(0.11,0.81))$ showed a statistically significant association with anxiety, whereas being married (AOR 2.67, 95\% Cl $(1.37,5.22)$ ), had stressful life event in the last six months (AOR 1.44, $95 \% \mathrm{Cl}(1.44,5.25)$ ) and spending of time by sleeping during the quarantine (AOR $1.97,95 \% \mathrm{Cl}(1.42$, 6.19)) predicted depression.

Conclusion: The current study result indicated that a considerable proportion of individuals who were under quarantine during the COVID-19 pandemic have experienced psychological disturbances, such as anxiety and depression. The presence of stressful life events, time spent on sleeping, and believing that COVID-19 could be prevented by wearing masks were found to be significant predictors of depression or anxiety among the participants. The results suggest that attention needs to be given to mitigate mental health problems in the quarantined population during the COVID-19 outbreak.

\section{Introduction}

Corona Virus Disease 2019 (COVID-19) is an infectious disease caused by a novel coronavirus (2019$\mathrm{nCoV}$ ) which was identified as a cause of a group of pneumonia cases in Wuhan, Hubei Province, China in December 2019 (1). It is highly infectious during the incubation period, and asymptomatic infection might exist. It has been affecting more than $92,767,845$ people resulting in more than 1986,696 mortalities worldwide (2) and it declared a Global Public Health Emergency (1). Also, in Africa, the virus has spread to dozens of countries within weeks, although governments and health authorities across the continent are striving to limit widespread infections more than one million COVID-19 cases reported (3). 
After the first case has been reported on March 13th of 2020 on Japanese citizens in Ethiopia (4), a total of 123,145 detected cases and 1912 deaths has reported (5). Due to the rapid and continuous spread of the infection, strong contagion, lethality in severe cases, and no specific medicine, it poses a huge threat to human life and health, and also has a huge impact on the mental health of the general public, causing people to a different degree of psychological problems $(6,7)$. In Ethiopia, as of January 14th, 2021, a total of 129,455 confirmed cases and 2,006 deaths have been reported (2).

For that matter, initially at the onset of the infection different countries of the world have been using quarantine to decrease the transmission of COVID-19 outbreak. This outbreak had seen entire cities in China effectively placed under mass quarantine, while many thousands of foreign nationals returned home from the COVID-19 outbreak area have been asked to self-isolate at home or in state-run facilities (8). Also, many countries of the world were declared quarantine. Quarantine is the separation and restriction of movement of people who have potentially been exposed to a contagious disease to ascertain if they become infected, so reducing the risk of them infecting others (9). It is differing from the word isolation, which is the separation of people who have been diagnosed with a contagious disease from people who are not sick (10). The word quarantine was first used in Venice, Italy in 1127 with regards to leprosy and was widely used in response to the Black Death (11).

Quarantine might have a wide-ranging, substantial, and long-lasting negative psychological impact on individuals as well as their family members $(12,13)$. The prevalence of psychiatric problems, including anxiety and depression, are high both during and after any infectious outbreaks $(14,15)$. During the initial phase of the COVID-19 outbreak, one-third of the individuals have moderate-to-severe anxiety and more than half of them rated the psychological impact as moderate-to-severe (16). These mental health problems could have a long-lasting effect on the mental health of the individual as well as the society, which hinders the urgent response to the current COVID-19 pandemic (14). Also, individuals with severe depressive symptoms are more susceptible to the severity of the pandemic (17). In addition, determinants such as female gender, student status, having specific physical symptoms, and poor self-rated health status are significantly associated with a greater psychological impact of the outbreak as well as higher levels of anxiety and depression (16). Further, factors such as longer quarantine duration, infection fears, frustration, boredom, inadequate supplies, inadequate information, financial loss, and stigma are also other sources of stressors (12). Whereas, factors like having specific up-to-date and accurate health information about the outbreak situation and particular precautionary measures like wearing personal protective equipment's (PPE) in the reverse has a significance association with a lower psychological impact of the outbreak and lower levels of anxiety, and depression (16).

Factors like a lower level of psychological impact and better mental health status can be used to formulate psychological interventions to improve the mental health of vulnerable groups during the COVID-19 epidemic (16). Taking appropriate psychological measurements on an individual under quarantine could reduce the negative mental impact (12). Because the psychological impact of stressful events related to an infectious disease outbreak may be mediated by enhancing peoples' perceptions of those events (18). Therefore, raising public awareness of the disease and providing positive 
psychological programs in the media aimed at controlling stress can reduce anxiety in society (7). Governments and healthcare authorities should take urgent actions to protect the mental health of their community (14) and should focus more on providing economic and medical support to improve the general population's mental state (15).

However, this is not to suggest that quarantine should not be used because the psychological effects of not using quarantine and allowing the disease to spread might be worse (19). Whereas, whenever quarantine is needed, depriving people of their liberty for the wider public good is often contentious and needs to be handled carefully and officials should take every measure to ensure that this experience is as tolerable as possible for people (12). Further, the provision of mental health first aid training and services during the quarantine period has paramount significance and benefit to individuals expected to be under quarantine (13). So, responsible health officials charged with implementing quarantine, are in employment and usually with reasonable job security, should also remember that not everyone is in the same situation (12).

In general, even if the government of Ethiopia in collaboration with other stakeholders has been trying to control and handle the COVID-19 outbreak, there is a gap in information that to what extent does those individuals experiencing psychological problems. So, the current study proposed with the aim to fill the gap by providing information about the magnitude of depression and anxiety among individuals under quarantine. Then the finding of the current study may also serve as a scientific reference to the health institutions and Ethiopian $\mathrm{FMOH}$ to offer comprehensive psychological support to individuals as well as their general population to minimize the psychological impact of every epidemic event and the mental problems. It may also serve as a reference for future studies and to develop appropriate policies and plans by the responsible health and other sectors.

\section{Methods And Materials}

\section{Study area, period, and design}

A community-based cross-sectional study was conducted from June 05 to July 05,2020 , at selected quarantine centers in Addis Ababa, Ethiopia. Addis Ababa is the capital city of Ethiopia, occupying a total area of $540 \mathrm{~km}^{2}$. The city is divided into ten sub-cities and 116 suburbs (Woredas). Initially, during the onset of COVID-19, the Ethiopian government shut down all Universities. And, all campuses of the Addis Ababa University, Addis Ababa Science and Technology University, governmental health colleges, and some selected hotels were assigned as quarantine centers. The number of individuals under quarantine varied from time to time, because it depends on the number of graduated individuals from the quarantine centers, travels to other regions, and a number of travels to Ethiopia from abroad. There were around 800 individuals under quarantine in Addis Ababa during the data collection period.

\section{Study population, sample size determination, sampling technique, and inclusion criteria}


All individuals who were under quarantine and available during the study period at the selected quarantine centers in Addis Ababa were the study population. The sample size was determined by using a single population proportion formula considering and assuming the proportion of depression and anxiety among individuals under quarantine to be $50 \%$, a $95 \%$ confidence level, and $5 \%$ degree of precision, the required sample size was estimated to be 384 .

After adding a non-response rate of $10 \%$; the final sample size was 422 . Around 1000 individual were expected to be under quarantine every month, so by considering this one we used the correction formula that is implemented when the source/study population are less than 10000, and the final sample size becomes 297 (adding 10\% =327). Regarding the sampling technique, first, we purposively selected the quarantine centers which were proposed by the government found in Addis Ababa. A simple random sampling technique was employed in order to select a representative sample of participants. The sampling frame was taken from the responsible office (EPHI \& Ethiopia FMOH) that control the overall situation of the quarantine centers. Then, individuals were selected by the lottery method.

\section{Data collection tools, procedure, management, and analysis}

A structured self-administered written questionnaire which had six sections was used to collect the data on socio-demographic characteristics (age, sex, and marital status), quarantine and clinical factors, psycho-social and substance-related factors.

Depression and anxiety were assessed by using the Hospital Anxiety and Depression Scale (HADS) (20). HADS is a 14 item questionnaire, extensively used to use to screen for depression and anxiety in Ethiopia $(21-23)$. The 14 items can be separated into two 7 item subscales for anxiety and depression. It is validated in Ethiopia and internal consistency is 0.78 for anxiety, 0.76 for depression, and 0.87 for full scale. The scale uses a cut-off score for depression and anxiety of greater than or equal to 8 (20).

The researchers recruited eight data collectors, and three supervisors (psychiatry/BSC nurses). The principal investigator supervised the whole activities of the data collection process. The training was delivered to data collectors and supervisors on how to use the questionnaire, the ethical principles of confidentiality, and data management before their involvement with data collection.

All questionnaires were checked for completeness and consistency of responses manually by the supervisors and researchers. After cleaning, data was entered into EPI-Data version 3.4 and was exported to SPSS version 25 for analysis. Descriptive statistics (frequencies and percentages) were used to explain the study participant in relation to study variables. Bivariate and multivariate analysis was used to determine the presence of statistically significant associations between the independent and dependent variables. All variables having a p-value $<0.05$ in the bivariate analysis were selected for the multivariable logistic regression to control for possible confounders. The strength of the association was presented in the odds ratio and $95 \%$ confidence interval. A p-value of $<0.05$ on multivariate analyses was considered statistically significant.

\section{Ethical considerations}


Ethical approval and clearance were obtained from Saint Paul's Hospital Millennium Medical College (SPHMMC) ethical review board. In addition, verbal consent of the respondents was obtained after giving information and thoroughly explaining the aim of the study to each respondent. The respondents were told that participation is voluntary, could withdraw at any time, or refuse to answer any question if they want to. The subjects were self-administrated questionnaires to maintain privacy. No information concerning the individual was passed to a third party.

\section{Results}

\section{Socio-demographic characteristics of the respondents}

A total of 297 participants were included in the study which makes the response rate $90.8 \%$. The mean age of the respondents was $28.33(\mathrm{SD}=6.22)$ years. Among the respondents, the majority $114(38.6 \%)$ were 25 years and below, 217(73.1\%) were female, 169(56.9\%) were unmarried, 153 (51.5\%) were Muslim religion members, $119(40.1 \%)$ had primary educational status, $241(81.1 \%)$ were Maid at abroad, 158 (53.2\%) were living at rural area of the country, 172 (57.9\%) had no child, 291 (98\%) were living with their family and $100 \%$ of them were living abroad before they joined the quarantine centers. Also, $209(70.4 \%)$ had 8000 Ethiopian birrs and below as a monthly income with a mean of 8783.74. (Table 1) 
Table 1

Descriptions of socio-demographic factors among individuals under quarantine during the Covid-19 pandemic, in Addis Ababa, Ethiopia, 2020.

\begin{tabular}{|c|c|c|c|}
\hline \multicolumn{2}{|l|}{ Variables } & \multirow{2}{*}{$\begin{array}{l}\text { Frequency } \\
114\end{array}$} & \multirow{2}{*}{$\begin{array}{l}\text { Percent (\%) } \\
38.6\end{array}$} \\
\hline Age & 25 and below & & \\
\hline & $26-30$ & 96 & 32.5 \\
\hline & 31 and above & 85 & 28.8 \\
\hline \multirow[t]{2}{*}{ Sex } & MALE & 79 & 26.6 \\
\hline & Female & 217 & 73.1 \\
\hline \multirow[t]{3}{*}{ Marital status } & Married & 105 & 35.4 \\
\hline & Single & 169 & 56.9 \\
\hline & Divorced & 23 & 7.7 \\
\hline \multirow[t]{4}{*}{ Religion } & Orthodox & 89 & 30.0 \\
\hline & Muslim & 153 & 51.5 \\
\hline & Protestant & 53 & 17.8 \\
\hline & Catholic & 2 & .7 \\
\hline \multirow[t]{5}{*}{ Educational status } & Unable to read and write & 22 & 7.4 \\
\hline & Able to read and write & 31 & 10.4 \\
\hline & Primary school & 119 & 40.1 \\
\hline & Secondary school & 105 & 35.4 \\
\hline & Certificate and above & 20 & 6.7 \\
\hline \multirow[t]{5}{*}{ Job } & Government employed & 1 & .3 \\
\hline & Student & 2 & .7 \\
\hline & Merchant & 19 & 6.4 \\
\hline & Unemployed & 33 & 11.1 \\
\hline & Other specify (maid) & 241 & 81.1 \\
\hline \multirow[t]{2}{*}{ Residence } & Urban & 139 & 46.8 \\
\hline & Rural & 158 & 53.2 \\
\hline \multirow[t]{2}{*}{ Have a child } & Yes & 125 & 42.1 \\
\hline & No & 172 & 57.9 \\
\hline
\end{tabular}




\begin{tabular}{|llll|}
\hline Variables & & Frequency & Percent (\%) \\
\hline Living with family & Yes & 6 & 2.0 \\
& No & 291 & 98.0 \\
Were living abroad & Yes & 295 & 99.3 \\
& No & 2 & .7 \\
Income & 8000 and below & 209 & 70.4 \\
\hline & $>8000$ & 88 & 29.6 \\
\hline
\end{tabular}

\section{Clinical and psychosocial characteristics}

Regarding clinical and psychosocial characteristics of the respondents, the majority $(270,90.9 \%)$ had no confirmed diagnosed chronic illness, and 159 (53.5\%) spent their time on Social Media including Facebook and YouTube during their stay at the quarantine center. About 148 (49.8\%) of them had intermediate social support and $173(58.2 \%)$ had no stressful life events in the last 6 months. Regarding substance use history, 234 (78.8\%) and $262(88.2 \%)$ had no ever used and within a month history of tobacco products consumption, $243(81.8 \%)$ and $283(95.3 \%)$ had no ever use and history of alcohol use within a month as well as $215(72.4 \%)$ and $293(98.7 \%)$ of the respondents had no ever use and history of amphetamine-related substance use within a month respectively. Further, all of them joined the center because of having a travel history to COVID-19 outbreak areas. (Table 2) 
Table 2

Description of clinical, psychosocial \& substance use factors among individuals under Quarantine for the case Covid-19 Pandemic, at Addis Ababa, Ethiopia, 2020.

\begin{tabular}{|c|c|c|c|}
\hline Variables & & Frequency & $\begin{array}{l}\text { Percent } \\
\text { (\%) }\end{array}$ \\
\hline Reason for quarantine & $\begin{array}{l}\text { History of traveling to the COVID-19 } \\
\text { outbreak area }\end{array}$ & 297 & 100.0 \\
\hline \multirow[t]{2}{*}{ Diagnosed chronic illness } & Yes & 27 & 9.1 \\
\hline & No & 270 & 90.9 \\
\hline \multirow[t]{4}{*}{ Type of co-morbid } & Diabetes & 2 & .7 \\
\hline & Renal disease & 7 & 2.4 \\
\hline & Hypertension & 11 & 3.7 \\
\hline & other specify & 6 & .7 \\
\hline \multirow{5}{*}{$\begin{array}{l}\text { Method of refreshment at the } \\
\text { quarantine center }\end{array}$} & Watching TV & 6 & 2.0 \\
\hline & Listening to a radio & 7 & 2.4 \\
\hline & $\begin{array}{l}\text { Using social media like Facebook, } \\
\text { YouTube etc.. }\end{array}$ & 159 & 53.5 \\
\hline & $\begin{array}{l}\text { Reading a book or other published } \\
\text { documents }\end{array}$ & 26 & 8.8 \\
\hline & by sleeping & 99 & 33.3 \\
\hline \multirow[t]{3}{*}{ social support } & poor social support & 114 & 38.4 \\
\hline & intermediate support & 148 & 49.8 \\
\hline & good social support & 35 & 11.8 \\
\hline \multirow[t]{2}{*}{ Stressful life events } & No & 173 & 58.2 \\
\hline & Yes & 124 & 41.8 \\
\hline \multirow[t]{2}{*}{ Ever use of tobacco products } & Yes & 63 & 21.2 \\
\hline & No & 234 & 78.8 \\
\hline \multirow[t]{2}{*}{ Ever use of alcohol } & Yes & 54 & 18.2 \\
\hline & No & 243 & 81.8 \\
\hline \multirow[t]{2}{*}{ Ever use of Amphetamine } & Yes & 82 & 27.6 \\
\hline & No & 215 & 72.4 \\
\hline Tobacco within a month & Yes & 35 & 11.8 \\
\hline
\end{tabular}




\begin{tabular}{|lllll|}
\hline Variables & & Frequency & $\begin{array}{c}\text { Percent } \\
\text { (\%) }\end{array}$ \\
\hline & No & 262 & 88.2 \\
\hline Alcohol use within a month & Yes & 14 & 4.7 \\
\hline Amphetamine use within a month & No & Yes & 283 & 95.3 \\
\hline & No & 4 & 1.3 \\
\hline
\end{tabular}

\section{Awareness of COVID-19 pandemic and PPE utilization}

The current study also showed that the vast majority of the respondents $(282,94.9 \%)$ had heard about the COVID-19 pandemic which roughly three fourth reported their source was from mass media (74.1\%). Two hundred six (69.4\%) and $183(61.6 \%)$ considered that COVID-19 is a disease of the respiratory tract and caused by a virus respectively. In addition, almost all agreed that COVID-19 can be prevented by using a facemask (98.3\%), wearing gloves (81.8\%), using a sanitizer (88.2\%), and keeping a physical distance (98.3\%). Concerning COVID-19 disease prevention methods utilization, 286 (96.3\%) reported that they were using a facemask, 281 (94.6\%) keep their physical distance, $253(85.2 \%)$ wash their hands, 151 $(50.8 \%)$ use a sanitizer whereas, only a small proportion (37.4\%) have used gloves. (Table 3 ). 
Table 3

COVID-19 related awareness and PPE utilization behavior of the study participants in at quarantine centers, in Addis Ababa, Ethiopia, 2020.

\begin{tabular}{|c|c|c|c|}
\hline Variables & & Frequency & $\begin{array}{l}\text { Percent } \\
(\%)\end{array}$ \\
\hline \multirow[t]{2}{*}{ Hear about the COVID-19 pandemic } & Yes & 282 & 94.9 \\
\hline & No & 15 & 5.1 \\
\hline \multirow[t]{7}{*}{ Source of information } & Mass media & 220 & 74.1 \\
\hline & Health professional & 7 & 2.4 \\
\hline & From my family & 14 & 4.7 \\
\hline & from my friends & 24 & 8.1 \\
\hline & Other & 17 & 5.7 \\
\hline & Hypertension & 11 & 3.7 \\
\hline & other specify & 6 & .7 \\
\hline \multirow[t]{6}{*}{ COVID-19 is caused by } & Bacteria & 17 & 5.7 \\
\hline & Virus & 183 & 61.6 \\
\hline & Fungus & 5 & 1.7 \\
\hline & Parasite & 3 & 1.0 \\
\hline & I don't know & 88 & 29.6 \\
\hline & Other & 1 & .3 \\
\hline \multirow[t]{3}{*}{ COVID-19 is } & Disease of the heart & 25 & 8.4 \\
\hline & $\begin{array}{l}\text { Disease of the respiratory } \\
\text { system }\end{array}$ & 206 & 69.4 \\
\hline & I don't know & 66 & 22.2 \\
\hline \multicolumn{4}{|c|}{$\begin{array}{l}\text { Which one of the following will help us to } \\
\text { prevent COVID-19 }\end{array}$} \\
\hline \multirow[t]{2}{*}{ handwashing } & Yes & 284 & 95.6 \\
\hline & No & 13 & 4.4 \\
\hline \multirow[t]{2}{*}{ Face mask } & Yes & 292 & 98.3 \\
\hline & No & 5 & 1.7 \\
\hline \multirow[t]{2}{*}{ By wearing gloves } & Yes & 243 & 81.8 \\
\hline & No & 54 & 18.2 \\
\hline
\end{tabular}




\begin{tabular}{|c|c|c|c|}
\hline Variables & & Frequency & $\begin{array}{l}\text { Percent } \\
\text { (\%) }\end{array}$ \\
\hline \multirow[t]{2}{*}{ By using sanitizer } & Yes & 262 & 88.2 \\
\hline & No & 35 & 11.8 \\
\hline \multirow[t]{2}{*}{ By keeping physical distance } & Yes & 292 & 98.3 \\
\hline & No & 5 & 1.7 \\
\hline \multicolumn{4}{|c|}{ Did you use the following to prevent COVID-19 } \\
\hline \multirow[t]{2}{*}{ Face mask } & Yes & 286 & 96.3 \\
\hline & No & 11 & 3.7 \\
\hline \multirow[t]{2}{*}{ Glove } & Yes & 111 & 37.4 \\
\hline & No & 186 & 62.6 \\
\hline \multirow[t]{2}{*}{ Sanitizer } & Yes & 146 & 49.2 \\
\hline & No & 151 & 50.8 \\
\hline \multirow[t]{2}{*}{ Hand washing } & Yes & 253 & 85.2 \\
\hline & No & 44 & 14.8 \\
\hline \multirow[t]{2}{*}{ Keep physical distance } & Yes & 281 & 94.6 \\
\hline & No & 16 & 5.4 \\
\hline \multirow[t]{2}{*}{ COVID-19 affect all age groups } & Yes & 239 & 80.5 \\
\hline & No & 58 & 19.5 \\
\hline
\end{tabular}

\section{The prevalence of anxiety, depression, and comorbid}

This study revealed that the prevalence of anxiety, depression, and co-morbid anxiety and depression was 21.5\% (Cl 16.8, 26.6), 70.7\% (Cl 65.7, 76.1), and 15.8\% (95\% C.I: 11.8, 20.2) respectively

\section{Factors associated with anxiety and depression Bivariate Analysis}

For each explanatory variable, bivariate analysis was done and socio-demographic factors such as having a child, stressful life event, spending the quarantine time by sleeping, and perceiving transmission of COVID-19 can be prevented by wearing of glove for anxiety and factors such as marital status, stressful life event, method of refreshment, source of information about COVID-19, perception on the cause of COVID-19, knowledge on method of prevention and utilization of COVID-19 prevention methods 
for depression were variables that fulfilled the minimum requirement of $p$-value $<0.05$ significance level for further multivariate logistic analysis.

\section{Multivariate Logistic Analysis}

In our multivariate analysis; factors such as those who had stressful life event in the last six months (AOR 2.61, 95\% Cl $(1.46,4.67)$ ), who spent their time sleeping during the quarantine (AOR $1.97,95 \% \mathrm{Cl}$ $(1.08,3.62))$, and those who considered COVID-19 could not be prevented by wearing gloves AOR 0.30, $95 \% \mathrm{Cl}(0.11,0.81))$ were statistically significant association with anxiety (Table 4$)$.

Table 4

Factors associated with anxiety among individuals under Quarantine for the case Covid-19 Pandemic, at Addis Ababa, Ethiopia, 2020

\begin{tabular}{|c|c|c|c|c|c|}
\hline \multirow[t]{2}{*}{ Explanatory Variables } & \multicolumn{2}{|c|}{ Anxiety } & \multirow[t]{2}{*}{$\mathrm{COR}, 95 \%(\mathrm{Cl})$} & \multirow[t]{2}{*}{ AOR,95\%(Cl) } & \multirow[t]{2}{*}{$\mathrm{p}$-value } \\
\hline & No & Yes & & & \\
\hline \multicolumn{6}{|l|}{ Have a child } \\
\hline No & 128 & 44 & 1 & 1 & \\
\hline Yes & 105 & 20 & $1.81,(1.00,3.25)$ * & $1.53,(0.82,2.84)$ & 0.181 \\
\hline \multicolumn{6}{|l|}{ Stressful life event } \\
\hline Yes & 85 & 39 & $2.72,(1.20,8.25)^{\star}$ & $2.61,(1.46,4.67)^{\star \star}$ & 0.001 \\
\hline No & 148 & 25 & 1 & 1 & \\
\hline \multicolumn{6}{|l|}{ Methods refreshment } \\
\hline By sleeping & 70 & 29 & $4.97,(1.10,3.40)^{\star}$ & $1.97,(1.08,3.62)^{\star \star}$ & 0.028 \\
\hline Other $^{1^{*}}$ & 163 & 35 & 1 & 1 & \\
\hline \multicolumn{6}{|c|}{ COVID-19 can be prevented by wearing gloves } \\
\hline Yes & 184 & 59 & 1 & 1 & \\
\hline No & 49 & 5 & $3.14,(1.20,8.25)$ * & $0.30,(0.11,0.81)^{\star \star}$ & 0.018 \\
\hline \multicolumn{6}{|c|}{ * Significant association ( $\mathrm{p}$-value $<0.05$ in bivariate) } \\
\hline \multicolumn{6}{|c|}{$\star \star$-significant association ( $p$-value $<0.05$ in multivariate analysis) Hosmer and Lemeshow test $=0.027$} \\
\hline
\end{tabular}

Whereas, being married (AOR 2.67, 95\% $\mathrm{Cl}(1.37,5.22)$ ), had stressful life event in the last six months (AOR $1.44,95 \% \mathrm{Cl}(1.44,5.25)$ ), and spending of time sleeping during the quarantine (AOR 1.97, 95\% Cl $(1.42,6.19))$ were significantly associated with depression. (Table 5). 
Table 5

Factors associated with depression among individuals under quarantine during the COVID-19 pandemic, in Addis Ababa, Ethiopia, 2020

\begin{tabular}{|c|c|c|c|c|c|}
\hline \multirow[t]{2}{*}{ Explanatory Variables } & \multicolumn{2}{|c|}{ Depression } & \multirow[t]{2}{*}{ COR,95\%(Cl) } & \multirow[t]{2}{*}{ AOR,95\%(Cl) } & \multirow{2}{*}{$\begin{array}{l}\text { p- } \\
\text { value }\end{array}$} \\
\hline & No & Yes & & & \\
\hline \multicolumn{6}{|l|}{ Marital status } \\
\hline Single & 63 & 106 & 1 & 1 & \\
\hline Married & 18 & 87 & $\begin{array}{l}2.87,(1.58 \\
5.21)^{*}\end{array}$ & $\begin{array}{l}\text { 2.67, }(1.37 \\
5.22)^{\star \star \star}\end{array}$ & 0.004 \\
\hline Divorced & 6 & 17 & $1.68,(0.63,4.49)$ & $\begin{array}{l}1.44,(0.50 \\
4.16)\end{array}$ & 0.503 \\
\hline \multicolumn{6}{|l|}{ Stressful life event } \\
\hline Yes & 23 & 101 & $\begin{array}{l}2.58,(1.49 \\
4.46)^{*}\end{array}$ & $\begin{array}{l}1.44,(1.44 \\
5.25)^{\star \star}\end{array}$ & 0.002 \\
\hline No & 64 & 109 & 1 & 1 & \\
\hline \multicolumn{6}{|l|}{ Methods of refreshment } \\
\hline By sleeping & 14 & 85 & $\begin{array}{l}3.55,(1.88 \\
6.69)^{\star}\end{array}$ & $\begin{array}{l}1.97,(1.42 \\
6.19)^{\star \star}\end{array}$ & 0.004 \\
\hline Other $^{1^{*}}$ & 73 & 125 & 1 & 1 & \\
\hline \multicolumn{6}{|l|}{ Source of information } \\
\hline From health professional & 4 & 3 & 1 & 1 & \\
\hline Mass media & 61 & 159 & $\begin{array}{l}3.48,(0.76 \\
15.98)\end{array}$ & $\begin{array}{l}2.46,(0.43 \\
13.92)\end{array}$ & 0.310 \\
\hline From family & 1 & 13 & $\begin{array}{l}17.33,(1.39 \\
216.60)^{\star}\end{array}$ & $\begin{array}{l}8.68,(0.60 \\
126.16)\end{array}$ & 0.114 \\
\hline from friend & 12 & 12 & $1.33,(0.24,7.28)$ & $\begin{array}{l}0.52,(0.71 \\
3.84)\end{array}$ & 0.524 \\
\hline Other & 3 & 14 & $\begin{array}{l}\text { 6.22,(0.89, } \\
43.66)\end{array}$ & $\begin{array}{l}1.58,(0.16 \\
15.58)\end{array}$ & 0.693 \\
\hline
\end{tabular}

* Significant association ( $\mathrm{p}$-value $<0.05$ in bivariate)

**-significant association ( $p$-value $<0.05$ in multivariate analysis) Hosmer and Lemeshow test $=0.022$

${ }^{1 *}$ other methods of refreshment $=$ Using social media (like Facebook, YouTube, etc..), Watching TV, listening to a radio and Reading a book or other published documents 


\begin{tabular}{|c|c|c|c|c|c|}
\hline \multirow[t]{2}{*}{ Explanatory Variables } & \multicolumn{2}{|c|}{ Depression } & \multirow[t]{2}{*}{ COR,95\%(Cl) } & \multirow[t]{2}{*}{ AOR,95\%(Cl) } & \multirow{2}{*}{$\begin{array}{l}\mathrm{p}- \\
\text { value }\end{array}$} \\
\hline & No & Yes & & & \\
\hline Virus & 66 & 117 & 1 & 1 & \\
\hline I don't know & 16 & 72 & $\begin{array}{l}2.54,(1.37 \\
4.72)^{\star}\end{array}$ & $\begin{array}{l}1.64,(0.68, \\
3.95)\end{array}$ & 0.274 \\
\hline Other & 5 & 21 & $2.37,(0.85,6.58)$ & $\begin{array}{l}2.68,(0.89, \\
8.06)\end{array}$ & 0.080 \\
\hline \multicolumn{6}{|c|}{$\begin{array}{l}\text { COVID-19 can be prevented by wearing } \\
\text { gloves }\end{array}$} \\
\hline Yes & 78 & 165 & 1 & 1 & \\
\hline No & 9 & 45 & $\begin{array}{l}2.36,(1.00 \\
5.08)^{\star}\end{array}$ & $\begin{array}{l}1.80,(0.63 \\
5.13)\end{array}$ & 0.271 \\
\hline \multicolumn{6}{|c|}{$\begin{array}{l}\text { COVID-19 can be prevented by using } \\
\text { sanitizer }\end{array}$} \\
\hline Yes & 82 & 180 & 1 & 1 & \\
\hline No & 5 & 30 & $\begin{array}{l}2.73, \\
(1.02,7 \cdot 30)^{*}\end{array}$ & $\begin{array}{l}\text { 2.07, (0.43, } \\
9.93)\end{array}$ & 0.362 \\
\hline \multicolumn{6}{|l|}{ Did you use sanitizer } \\
\hline Yes & 52 & 94 & 1 & 1 & \\
\hline No & 35 & 116 & $\begin{array}{l}1.83,(1.04 \\
3.05)^{\star}\end{array}$ & $\begin{array}{l}1.57,(0.83 \\
2.99)\end{array}$ & 0.169 \\
\hline \multicolumn{6}{|c|}{ * Significant association ( $p$-value $<0.05$ in bivariate) } \\
\hline \multicolumn{6}{|c|}{ **-significant association ( $\mathrm{p}$-value $<0.05 \mathrm{in}$ multivariate analysis) Hosmer and Lemeshow test $=0.022$} \\
\hline
\end{tabular}

\section{Discussion}

To the best of our knowledge, this is the first study to explore the prevalence and factors associated with anxiety and depression among in quarantined population during the COVID-19 outbreak in Sub-Saharan Africa including Ethiopia. Our final analysis revealed a high prevalence of anxiety, depression, as well as comorbid anxiety and depression among the participants. The prevalence of anxiety in this study (21.5\%) was higher than the previous study finding conducted in southwestern China (8.3\%)(24) and lower than other studies conducted in different countries including China $(28.8-58 \%)(16,17)$, Huwan (70.78\%) (25), Sierra Leone (48 \%) (26), Australian (34\%) (27) and the global prevalence based on finding from a recent meta-analysis (45\%)(14). The discrepancy in the finding of the current study and the previous studies 
could be the difference in factors influencing the prevalence of anxiety such as sample size and instrument used $(14,16,17,24,26,27)$ and differences in characteristics of the study participant across the studies $(14,26,27)$.

Regarding associated factors of anxiety, in the current study, those who had stressful life events in the last six months were 2.61 times more likely to have anxiety symptoms as compared to those who hadn't. The psychological impact of stressful events could have related to an infectious disease outbreak (18). Further, factor such as frustration, inadequate supplies, and financial loss are among the different stressful life events which could provoke individuals to experience anxiety (12).

Individuals who spent their time sleeping during the quarantine period were 1.97 times more likely to experience anxiety symptoms based on the hospital anxiety and depression scale as compared to those who spent their time using different social media and mass media. This might be because receiving different refreshing information and games through these social media's as well as mass media's could help the individuals to experience more relaxation and exposure with others. Lack of social support or rejection of oneself from social aspects could exposed peoples to develop more psychological impacts like anxiety(14).

Moreover, those who considered COVID-19 infection couldn't have prevented by wearing the glove were more likely to have anxiety as compared to those who considered it could prevent. This could be associated with the type of information they received and their way of interpretation. But the current study finding is in contrast with others that inadequate information (26) with a high level of stress, whereas having specific up-to-date and accurate health information and particular precautionary measures like gloves are associated with a lower psychological impact of the outbreak (27).

Regarding the prevalence and factors associated with depression among individuals under Quarantine for the case Covid-19 Pandemic, the current study result determined that the prevalence of depression was $70.7 \%$ which is high. The high prevalence might be related to being separated from close families and friends because social isolation and lockdown can lead to psychological disturbance (28). Quarantine may have a detrimental impact on mental health which can increase psychiatric symptoms and mental health problems in the general population (29). Thus, even if quarantine has a wide-ranging, substantial, and long-lasting psychological impact, it is not to suggest that quarantine should not be used; because of the psychological effects of not using quarantine and allowing the disease to spread might be worse(30). But, it is better to recognize its psychological impact as well as the rapid spread of the COVID-19 pandemic as a public health priority for both authorities and policymakers who should rapidly adopt clear behavioral strategies to reduce the burden of disease and the dramatic mental health consequences of this quarantine related to the current pandemic (31). Our finding is higher than the reported results from studies which were conducted in China (14.6-27.9\%) $(16,24,32)$, Hong Kong (19\%) (33), Huwan (26.47\%) (25), and the global prevalence on finding from a meta-analysis (28\%)(34). Further, it was also quite higher than study results of different countries like Sierra Leone that any anxietydepression symptom was reported among $48 \%$ of the general population (26), around $15 \%$ of the 
university students living in Bangladesh (35), $6.21 \%$ in Shenzhen (36), in Albania $6.22 \%$ and $6.28 \%$ of bachelor and master university students (nurses/midwives) and their family members' respectively reported symptoms of depression (13) and as per the systematic rapid review and meta-analysis study result, $38 \%$ of the healthcare workers' $(\mathrm{HCWs})$ were reported depression symptoms (14). The differences in the methodologies used and the characteristics of the participants might be the possible reasons for the observed variations.

Concerning the associated factors of depression those who were married are 2.67 times more likely to have depression symptoms based on HAD data collection tool that we used as compared to those who were single. This could be due to separation from their sexual partner and more worry about their family. Quarantine experience has a positive correlation with depressive symptoms, while home quarantine is positively correlated with happiness (17).

In addition, those who had experienced stressful life events in the last six months had 1.44 times more likely to have depression as compared to those who hadn't. Stressful life events by itself it has its own contribution in the development or exposing individuals to experience more depression symptoms. Being more worried about being infected, having no psychological support, greater property damage, and lower self-perceived health condition has a significant association with higher scores of self-rating depression scale (24). Also, having specific physical symptoms, principal financial problems or loss (27), infection fears, frustration, inadequate information, and stigma has a great risk of developing psychological problems like depression (12).

With respect to methods of refreshment or way spending time during the quarantine period, the current study found that those who were spending their time by sleeping were 1.97 times more likely to have a high score of depression symptoms as compared to those who were spent their time by using social media (like Facebook, YouTube, etc..), watching TV, listening radio and reading a book or other published documents. But this was in contrast with the previous study report because it was mentioned frequent exposure to social media as a risk factor for depression (37).

\section{Conclusion}

In summary, in this study, more than one fifth and about three fourth of the participants had anxiety and depression respectively, suggesting anxiety and depression requires attention in quarantined population during the COVID-19 outbreak. Moreover, roughly one-sixth of the participant had comorbid anxiety and depression. The presence of stressful life events, time spent on sleeping, and believing that COVID-19 could be prevented by wearing masks were found to be significant predictors of depression or anxiety among the participants. The results suggest that attention needs to be given to mitigate mental health problems in the quarantined population during the COVID-19 outbreak,

\section{Abbreviations}


AOR; Adjusted Odd Ratio

COVID-19; Coronavirus disease

Cl; Confidence Interval

COR; Crude Odd Ratio

FMOH; Federal Ministry of Health

SARS; Severe acute respiratory syndrome

SPHMMC; Saint Paul's Hospital Millennium Medical College

SPSS; Statistical Package for Social Sciences

WHO; World Health Organization

\section{Declarations}

\section{Ethics approval and consent to participate}

The current manuscript had got ethical approval from Saint Paul's Hospital Millennium Medical College (SPHMMC) IRB. In addition, informed consent was obtained from all study participants before they enrolled in the study. They were told that their participation is voluntary, could withdraw at any time, or refuse to answer any question if they want to. We were used a self-administrated written questionnaire to maintain privacy. No information concerning the individual was passed to a third party. So, in general, we carried out the current research by fulfilling all the requirements of the institutional (SPHMMC) IRB guidelines and regulations and also it fulfilled the Declaration of Helsinki guidelines and regulations.

\section{Availability of data and materials}

The datasets used and analyzed during the current study are available from the corresponding Author on reasonable request.

\section{Consent for publication}

Further, informed consent for publication was also obtained from each study participant under the consent form by mentioned for all of them that the data will be published in international journals. So, this is to confirm that informed consent for publication was obtained from all the study participants. The collected data is kept confidentially under the primary investigator and co-investigators.

\section{Acknowledgments}


The authors acknowledge saint Paul Hospital Millennium Medical College IRB of the institution for their ethical evaluation and approval. Also, for the institution Academic and Research Vice provost and research directorate office for sponsoring the research proposal. The authors appreciate the respective study institution and the study participants for their cooperation in providing the necessary information.

\section{Authors' contributions}

MA was involved starting from conceiving the idea, developing the proposal, the study design, reviewed the article, analyzing, report writing, and drafted and write up the manuscript; GA was involved in reviewing and developing the proposal, report, and manuscript; DB, AG, MB, MG, MS, AM, SD, GT \& TS were involved in reviewing the proposal and manuscript, but MS was also involved in the data collection process.

\section{Funding}

There is no source of funding for the current manuscript

\section{Competing interest}

All authors read and approved the final manuscript. The authors declare that they have no competing interests.

\section{References}

1. Organization WH. Clinical management of severe acute respiratory infection when Novel coronavirus (nCoV) infection is suspected: interim guidance December 29th of 2020. infection-when-novelcoronavirus- (ncov)-infection-is-suspected Jan 30, 2020.

2. updated wl. January 14 th of 2021.

3. Medicine SEGfCotEoNCPotCP. An update on the epidemiological characteristics of novel coronavirus pneumonia (COVID-19). Chinese Journal of Epidemiology. 2020; 41(2):139-44.

4. 2020 EcfccLuacAftooM. aljazeera.com from the original on 13 March 2020. 13 March 2020.

5. Coronavirus Worldometer E. January 14 of 2021.

6. Gao JL ZP, Jia YN, et al Mental Health Problems and Social Media Exposure during COVID-19 Outbreak. 2/17/2020.

7. Fardin MA. COVID-19 and Anxiety: A Review of Psychological Impacts of Infectious Disease Outbreaks. Arch Clin Infect Dis. 2020 April;15(COVID-19)(102779).

8. England PH. Novel coronavirus (2019-nCoV) - what you need to know. 2020.

9. Prevention CfDCa. Quarantine and isolation. 2017. Jan 30, 2020

10. Manuell M-E CJ. Mother Nature versus human nature: public compliance with evacuation and quarantine. Disasters 2011; 35(417-42). 
11. K N. Shutt up: bubonic plague and quarantine in early modern England. J Sol Hist 2012 45(809-34).

12. Samantha K Brooks RKW, Louise E Smith, Lisa Woodland, Simon Wessely, Neil Greenberg, Gideon James Rubin. The psychological impact of quarantine and how to reduce it: rapid review of the evidence 2020;20(S0140-6736):30460-8.

13. Enkeleint A. Mechili AS, Fatjona Kamberi, Charis Girvalaki, Ela Peto, Athina E. Patelarou, Jorgjia Bucaj, Evridiki Patelarou. Is the mental health of young students and their family members affected during the quarantine period? Evidence from the COVID-19 pandemic in Albania. J Psychiatr Ment Health Nurs. 2020;00(1-9).

14. Ignacio Ricci-Cabello JFM-E, Maria Jesús Serrano-Ripoll, et al. IMPACT OF VIRAL EPIDEMIC OUTBREAKS ON MENTAL HEALTH OF HEALTHCARE WORKERS: A RAPID SYSTEMATIC REVIEW. medRxiv preprint. 2020.

15. Joseph T. F. Lau SG, c Kai-chow Choi, and Chunqing Lin. Prevalence of preventive behaviors and associated factors during early phase of the H1N1 influenza epidemic Am J Infect Control 2010;38(374-80).

16. Cuiyan Wang RP, Xiaoyang Wan, Yilin Tan, Linkang Xu , Cyrus S. Ho and Roger C. Ho. Immediate Psychological Responses and Associated Factors during the Initial Stage of the 2019 Coronavirus Disease (COVID-19) Epidemic among the General Population in China. Int J Environ Res Public Health. 2020;17(1729).

17. Lu HN, Peng; Qian, Long Do Quarantine Experiences and Attitudes Towards COVID-19 Affect the Distribution of Psychological Outcomes in China? A Quantile Regression Analysis, GLO Discussion Paper,. Global Labor Organization (GLO), Essen. 2020(512).

18. Ping Wu YF, Zhiqiang Guan, Bin Fan, Junhui Kong. The Psychological Impact of the SARS Epidemic on Hospital Employees in China: Exposure, Risk Perception, and Altruistic Acceptance of Risk Can J Psychiatry. 2009;54(5):302-11.

19. HF H. SARS control and psychological effects of quarantine, Toronto, Canada. Emerging Infectious Diseases 2005. 2005;11(354-55).

20. AA R. Reliability and validity of the Ethiopian version of the hospital anxiety and depression scale (HADS) in HIV infected patients. PLoS ONE. 2011;6(1).

21. Kebede MA AB, Ayano G. Prevalence and predictors of depression and anxiety among medical students in Addis Ababa, Ethiopia. Int J Ment Health Syst. 2019;6(13):30.

22. Tesfaw G, Ayano, G., Awoke, T. et al. Prevalence and correlates of depression and anxiety among patients with HIV on-follow up at Alert Hospital, Addis Ababa, Ethiopia. BMC Psychiatry 16(368).

23. Ayano G, Solomon, M. \& Abraha, M. A. systematic review and meta-analysis of epidemiology of depression in people living with HIV in east Africa. BMC Psychiatry 2018;18(254).

24. Lei Lei XH, Shuai Zhang, Jinrong Yang, Lin Yang, Min Xu. Comparison of Prevalence and Associated Factors of Anxiety and Depression Among People Affected by versus People Unaffected by Quarantine During the COVID-19 Epidemic in Southwestern China. Med Sci Monit. 2020;26(924609). 
25. Fang Tang JL, Hai Zhang, Mohammedhamid Mohammedosman Kelifa, Qiqiang He \& Peigang Wang COVID-19 related depression and anxiety among quarantined respondents. Psychology \& Health. 2020.

26. Jalloh MF LW, Bunnell RE, et al. 26. Jalloh MF, Li W, Bunnell RE, et al. Impact of Ebola experiences and risk perceptions on mental health in Sierra Leone, July 2015. BMJ Glob Health 2018;3:e000471. doi:10.1136/ bmjgh-2017-000471. BMJ Glob Health. 2018;3(e000471).

27. Melanie R Taylor KEA, Garry J Stevens and Beverley Raphael. Factors influencing psychological distress during a disease epidemic: Data from Australia's first outbreak of equine influenza. BMC Public Health 2008;8(347).

28. NATIONAL INSTITUTE OF MENTAL HEALTH \& NEUROSCIENCES B, INDIA. Mental Health in the times of COVID-19 Pandemic Guidance for General Medical and Specialized Mental Health Care Settings APRIL - 2020. 2020.

29. Giallonardo V SG, Del Vecchio V, Luciano M, Albert U, Carmassi C, Carrà G, Cirulli F, Dell'Osso B, Nanni MG, Pompili M, Sani G, Tortorella A, Volpe U and Fiorillo A The Impact of Quarantine and Physical Distancing Following COVID-19 on Mental Health: Study Protocol of a Multicentric Italian Population Trial. Front Psychiatry 2020;11(533).

30. Samantha K Brooks RKW, Louise E Smith, Lisa Woodland, Simon Wessely, Neil Greenberg, Gideon James Rubin. The psychological impact of quarantine and how to reduce it: rapid review of the evidence Lancet 2020;395(912-20).

31. G. Serafini BP, A. Amerio, A. Aguglia, L. Sher, and M. Amore. the psychological impact of COVID-19 on the mental health in the general population. QJM: An International Journal of Medicine. 2020( 529535).

32. Edmond Pui Hang Choi BPHHaEYFW. Depression and Anxiety in Hong Kong during COVID-19. Int J Environ Res Public Health. 2020;17(3740).

33. Le Shi Z-AL, Jian-Yu Que, Xiao-Lin Huang, Lin Liu, Mao-Sheng Ran, Yi-Miao Gong, Kai Yuan, Wei Yan, Yan-Kun Sun, Jie Shi, Yan-Ping Bao, Lin Lu. Prevalence of and Risk Factors Associated With Mental Health Symptoms Among the General Population in China During the Coronavirus Disease 2019 Pandemic. JAMA Network Open. 2020;3(2014053):14053.

34. Ma XRWHHPTHXWY. Mental Health During the Covid-19 Outbreak in China: a Meta-Analysis. Psychiatric Quarterly 2020;91(1033-1045).

35. Md. Akhtarul Islam SDB, Hasin Raihan, Md. Nafiul Alam Khan, Md. Tanvir Hossain. Depression and anxiety among university students during the COVID-19 pandemic in Bangladesh: A web-based crosssectional survey. PLoS ONE 2020;16(0238162):8.

36. Min Penga BM, Yansong Liub , Mingming Xub , Xinran Songa , Luyu Liua, Yeqing Fangb , Tianyou Guoc, Jinying Yec, Zhijian Yud, Qiwen Dengd, Xiangyang Zhang. Prevalence, risk factors and clinical correlates of depression in quarantined population during the COVID-19 outbreak. Journal of Affective Disorders 2020;275(119-124). 
37. Ruth Flynn ER, Garth Reid, Alix Rosenberg and Claire Niedzwiedz. Rapid review of the impact of COVID-19 on mental health. Edinburgh: Public Health Scotland. 2020. 